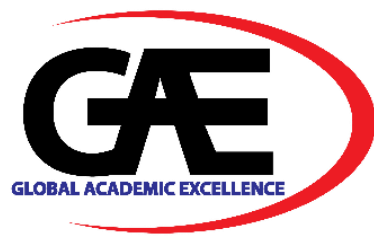

\title{
INJECTING EDUCATIONAL ELEMENT IN LAWS AND REGULATIONS OF CHILD CARE CENTRES IN MALAYSIA
}

\author{
Mashitah Abdul Mutalib ${ }^{1 *}$, Nur Amalina Abdul Ghani ${ }^{2}$ \\ 1 Faculty of Syariah and Law, Universiti Sains Islam Malaysia, Malaysia \\ Email: mashitahmutalib@usim.edu.my \\ 2 Faculty of Business Management and Professional Studies, Management Science University, Malaysia \\ Email: nuramalina_abdghani@msu.edu.my \\ Corresponding Author
}

\section{Article Info:}

Article history:

Received date: 04.10 .2021

Revised date: 21.10 .2021

Accepted date: 10.11.2021

Published date: 01.12.2021

\section{To cite this document:}

Mutalib, M. A., \& Ghani, N. A. A. (2021). Injecting Educational Element In Laws And Regulations Of Child Care Centres In Malaysia. International Journal of Law, Government and Communication, 6 (26), 61-68.

DOI: 10.35631/IJLGC.626006.

This work is licensed under CC BY 4.0

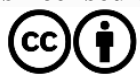

\begin{abstract}
:
The aim of regulating child care centres should not just be limited to providing protection in terms of the children's safety and health. It should go beyond providing a 'safe haven' in order to enhance the potentials of the children. Therefore, the element of learning and education should be included as one of the legal requirements in regulating child care centres. This paper, therefore, examines the question of whether the educational element should be enacted in the legislative framework of Malaysian child care. The qualitative method is used in this study using document analysis. The laws and regulations on child care centres especially Child Care Centre Act 1984 are evaluated. Apart from the laws and regulations in Malaysia, analysis on international experiences of various jurisdictions which may be taken as lessons for Malaysia is also conducted in enhancing the laws and regulations of Malaysian child care. It is submitted that educational element is an important element to be embedded in laws and regulations governing child care centres in Malaysia early childhood apart from other legal requirements.
\end{abstract}

Keywords:

Child Care, Education, CCCA1984

\section{Introduction}

Entering the twenty-first century, the importance of regulating child care is not just limited to protecting the children in order to provide a "safe haven" but it goes beyond that purpose in ensuring that the children's potentials are enhanced through the element of learning and education (Gallagher et al., 1999). Therefore, one of the effective legal requirements that should not be left out in child care and regulations is the regulation on educational programme in child care centres. 


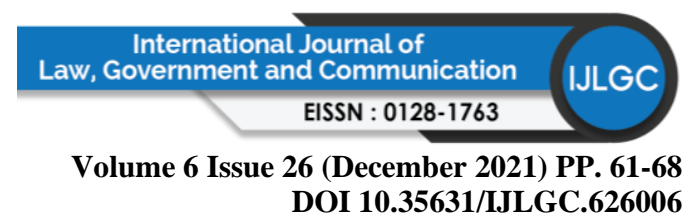

Educational programme is sometimes used in different terms such as curriculum or learning standards. Basically, it contains contents and methods on what to teach and how to teach. It covers relations, experiences, activities, events which inculcate good developments in children (Taguma et al., 2013). The term "education program" refers to any program that is primarily concerned with the provision of education, such as early childhood education, elementary and secondary education, postsecondary education, special education, job training, career and technical education, and adult education, as well as any program administered by an educational agency or institution. Meanwhile, Section 41 of the United Kingdom Childcare Act 2006 defines educational programmes as 'the matters, skills and processes which are required to be taught to children of different abilities and maturities. It may also be defined as the "areas of learning and development which must shape activities and experiences for children” (United Kingdom Department for Education, 2017).

Educational programme consists of contents of the activities of the children which are sometimes termed as curriculum. The activities provided for the children is considered as process quality but the aspect that may be regulated is the plan or education programme that legislate the obligation to implement the plan and education program according to the approved curriculum or framework. In a study in 2015 on the association of education programme towards educational process quality, it has been found that, there is moderate association (Slot et al., 2015). It is concluded that this result is in line with previous research that found positive impacts of educational programme towards quality and good outcomes of the children.

It is a need to have proper planning of curriculum as this document aside from assisting in ensuring good impacts for the children's growth and for school preparation (Hanafi, 2015) the curriculum will manoeuvre the operators and child care providers as to what activities that should be carried out with the children, as well as the reasons why these activities are chosen (Debbie \& McCormilla, 2012). Therefore, crucial learning will not be missed by the children and there is a continuity of learning and education from the early years in the child care centres to the subsequent stages i.e. pre-school and school age (OECD, 2012). Furthermore, this is one of the methods for the parents to know the experiences and interactions the children are acquiring in the child care centres. In addition, another importance of planning a curriculum is that it is a method to measure the performance of the child care providers in reflecting for a better planning in future (Debbie \& McCormilla, 2012). Looking at the practise in Korea for instance, it is claimed that one of the most vital elements of quality is to ensure that the children undergo and experience quality activities. Therefore, it has been the focus of the government to develop a standard childcare framework appropriate to the level of the age of the children (Rhee \& Duksung, 2007).

\section{International Practices}

Looking at international practices, New Zealand and Nordic countries too have curriculum which arrange the contents from birth or one year to school age. The 'TeWhariki' of New Zealand divides the children into three categories which are infants for children from birth until 18 months, toddlers for children from one to three year old, and young children for children from two and half years to school age. It is interesting to note that, more countries are now moving towards integrating their childcare and preschool curriculum so that there is continuity in the process of learning from early years until school age. Korea with their Nuri Curriculum is integrating the curricula for childcare and preschool while Japan is integrating its National 


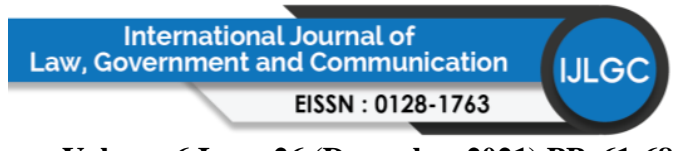

Volume 6 Issue 26 (December 2021) PP. 61-68

DOI 10.35631/IJLGC.626006

Curriculum of Day Care Centres with the Course of Study for Kindergartens (United Kingdom Department of Education, 2013).

The school day in England began as early as three years old and is considered mandatory for parents who live in the United Kingdom to send their children to school on a daily basis. Interestingly, the United Kingdom considered knowledge to be an important component of the country's development, and as a result, education is provided free of charge unless children are sent to a private school. The United Kingdom's four nations have increasingly pursued divergent educational policies since devolution in 1999, with England focusing on increasing school autonomy while Scotland, Wales and Northern Ireland abolished league tables and external testing in favour of more localized evaluations.

It is further claimed that the importance of an educational programme to be implemented in child care settings should be supported by strong provision on the supplemented factors such as ratio, group size and trainings of the child care providers. This is relevant as it would be useless if the comprehensive well-planned education programme is not understood well by the one who will be responsible to implement the activities. Therefore, an educational programme should come into the picture when other factors such as staffing issues are accordingly regulated and adhered by child care operators and providers. Correspondingly, in the Malaysian context the provision on ratio is already in existence and the ratio is low and satisfactory. Notably, there is a need to introduce the group size provision and to polish up the provision on trainings of the child care providers, physical environments, and health and safety features.

Thus, in regulating the educational program or curriculum, a country should first strengthen the other significant features such as adult to child ratio, group size, staff's welfare and professionalism, educational equipment and so on (Taguma et al., 2012). This is relevant for the comprehensiveness of the curriculum, frameworks will not be fully utilised or optimised if the child care providers are neither ready nor aware to seek adequate support in implementing the content of the curriculum. Therefore, the effort to introduce the curriculum in the preservice training is important. However, this effort should be further complimented by the readiness of the child care providers to utilise the curriculum. Moreover, continuous trainings for the child care providers shall be a good avenue to equip the operators and the child care providers with the relevant information and the effective method in implementing the curriculum for the best interest of the children. The introduction of technology for instance should be learned by the child care providers in adapting the curriculum contents to the rapid progress of the digital world today (Taguma et al., 2012).

For instance, in Australia nationwide training of early childhood educators is under the responsibility of a non-government organisation which is hired on contract basis to guide the educators in the implementation of the Early Years Learning Framework (EYLF) (United Kingdom Department of Education, 2013). It is highlighted that the success of the implementation of the curriculum in Australia is due to the participation of the stakeholders in drafting the curriculum which indirectly create the sense of belonging. Secondly, pertaining to the linguistic aspect, instead of the use of unfamiliar jargons the language chosen in drafting the curriculum is simple and common which in turn assist the staff and even the parents to better understand the curriculum, and in depth. 


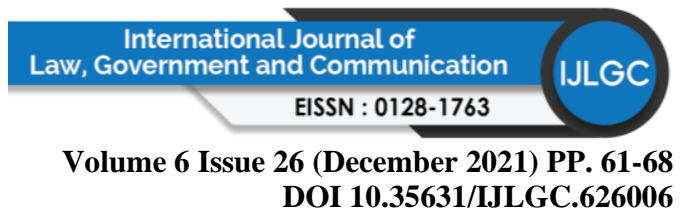

\section{Malaysian Position}

In Malaysia, previously, there is no uniformed curriculum to be implemented in child care centres. The content of the basic compulsory course is mainly on the feature of health and safety. Therefore, the aspect of education is left to the child care providers to decide; what type of education they will provide to the children. Nevertheless, PERMATA curriculum has now been approved to be the guideline for the creation of "Kurikulum Asuhan dan Didikan Awal Kanak-Kanak Kebangsaan”. During its pioneer project from 2007 to 2009, the curriculum has been revised a few times and has been developed and acknowledged as the National Curriculum under the Child Care Education and Early Education Policy in 2008 (Bahagian Pendidikan Awal Kanak-Kanak PERMATA, 2013).

However, analysing the legislations of child care in Malaysia, particularly CCCA 1984 and CCCR 2012, there is no specific statutory provision that addresses the educational programme though there is a requirement for the child care providers to attend PERMATA Early Child Care and Education Course which applies the National Early Childhood Care and Education Curriculum.

In addition, with regard to the schedule of activities of the children, there is only a general requirement that has been made by CCCA 1984 under Section 8 (e) where one of the terms and conditions for registration is for the provider to arrange a suitable schedule for feedings, resting and recreation for the children in the child care centre.

Meanwhile, in CCCR 2012, child care activities are regulated under Part XII. Regulation 38 (1) (a) details that the schedule should include indoor and outdoor activities suitable to the age and development of the children, and routine activities such as feedings, resting, sleeping, bathing and so on. Failure to arrange for this schedule shall constitute an offence punishable with a fine not exceeding RM 1000 or imprisonment not exceeding six months. According to Regulation 40, this schedule must be displayed in a conspicuous place. It is also interesting to note that under Regulation 41 (2), the children should not be forced to be involved in the activities and the outdoor session should not be more than 30 minutes.

Nevertheless, these legislations are merely schedule of activities that mainly involve routine activities. The structural feature which is recommended by the scholars to be regulated is the educational programme which is neither found in CCCA 1984 nor CCCR 2012.

Notably, the curriculum in child care centres which is Kurikulum Asuhan PERMATA is known by child care providers especially by those who have undergone PERMATA Early Child Care and Education Course. However, it is reported that although the implementation of this curriculum has been required since January 2013, not every child care centre is aware of the existence of the curriculum, and to worsen the situation, there are child care centres which implement the curriculum for pre-school or TADIKA 2013 (UNITAR International University, 2017). Furthermore, it is reported that child care providers who are aware of the requirement to use the curriculum fail to do so in their centres. The schedule activity is just for the sake of registration and has not been implemented in the day-to-day activities of the children in these child care centres. This situation may be remedied by inserting clearly in the laws and regulations the requirements of the educational programme or the specified curriculum to be implemented in child care centres. 


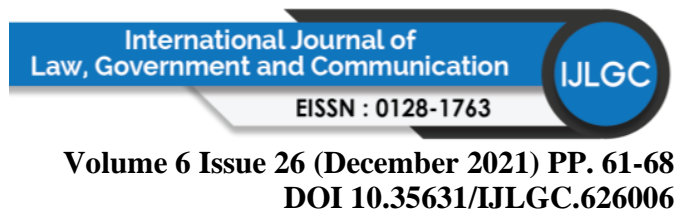

\section{How is Education Element Regulated in other Jurisdictions?}

Basically, in Australia there are two national approved learning frameworks. The first is 'Belonging, Being and Becoming- The Early Years Learning Framework for Australia', and the second is 'My Time, Our Place' which is a framework for school age children (Debbie \& McCormilla, 2012). From 1st. February 2018, the National Quality Standard of Australia has made several changes which include the approved learning framework. It has now been defined as the "curriculum decision-making contributes to each child's learning and development outcomes in relation to their identity, connection with community, wellbeing, confidence as learners and effectiveness as communicators" (Australian Children's Education and Care Quality Authority, 2017).

Looking at how Australia regulates its educational programme, the legal obligation to implement educational program can be seen in Section 168 of Education and Care Services National Law Act 2010, specifically under the operating an education and care service part. Section 168 states:

'The approved provider of an education and care service must ensure that a program is delivered to all children being educated and cared for by the service that - (a) is based on an approved learning framework; and(b) is delivered in a manner that accords with the approved learning framework; and (c) is based on the developmental needs, interests and experiences of each child; and(d) is designed to consider the individual differences of each child. Penalty: $\$ 4000$, in the case of an individual. \$20 000, in any other case'.

Thus, this Section mentions that the provider or nominated supervisor must ensure that the program is based on an approved learning framework and is to be implemented according to the framework. This programme must also stress on developmental needs of the children, and their interests and experiences. In addition, the differences and uniqueness of each of the children should be considered in drafting and implementing the framework. It is stipulated under this Section that it is an offence not to implement this programme according to the approved learning framework and this is punishable with a fine of $\$ 4,000$.

This is further detailed in the Education and Care Services National Regulations 2012, in Part 4.1 on educational programmes and practice encompassing Regulation 73 until Regulation 76. The educational programme must aim to establish certain required outcomes- mainly on a strong identity for the child, connection and contribution of the child to his or her world and a strong sense of wellbeing. Besides that, the program should be able to nurture children to be confident and to be an involved learner, and to be able to communicate effectively. These outcomes may be measured through assessments and evaluations which are documented according to the developmental needs, interests, experiences, and participation in the program. Assessment may also be made assessing the progress of the child as against the educational programme outcomes.

There are certain matters that need to be considered by the child care operators in terms of the documentation of the education programme. First, the period of time the children are being cared for and the manners on how the documentation will be used by the child care providers. In addition, the documents must be understandable by the child care providers and the parents. Moreover, the educational program information and contents must be displayed at the premises to be accessible to the family members and for inspection. Furthermore, the parents will also 


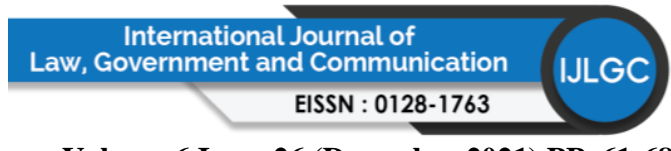

Volume 6 Issue 26 (December 2021) PP. 61-68

DOI 10.35631/IJLGC.626006

be provided with the content and operation of the educational programme and on how their children participate in the programme.

In addition, there is the requirement to appoint an educational leader to lead the implementation of the educational programme. The educational leader must have full grasp of the contents of the curriculum which is EYLF for early years as he is responsible to guide other educators in carrying out the curriculum. This is found under regulation 118 (Debbie \& McCormilla, 2012).

Meanwhile, in Singapore, in the previous child care regulations, there is no mention of any regulated curriculum or education programme in the regulations. However, under the new act that has been passed by the Parliament in 2017, one of the elements that the Minister may make is the regulations on the types and content of the curriculum that is to be implemented in the centres as mentioned in Section 52. This illustrates that Singapore is reforming its early childhood care and its education has highlighted the importance of education of curriculum, to be regulated in its regulations.

All in all, an appropriate educational programme should also be regulated complimenting the other important features such as ratio, health and safety (Burchinal et al., 2015). The curriculum has been regulated in a few countries through inserting the requirement to have curriculum frameworks in their laws and regulations. A few countries such as New Zealand, Norway, Australia and Sweden have regulated their education programme in child care centres since 1996. It is interesting to note that this is the first time the curriculum has been legislated in their legislations for several reasons. One of the reasons is the recognition of the importance of early childhood. The need to regulate this feature is one of the ways in raising the status of the sector in the countries' priorities or agenda (Oberhuemer, 2005). It is claimed that, almost all developed countries have curriculum frameworks either as a set of mandatory curricula or as statutory requirements; they have it in sets of guidelines (United Kingdom Department of Education, 2013). Therefore, it is high time for Malaysia to improvise or set regulatory standards on child care centres by giving focus to legislate the requirement to have curriculum frameworks.

On another note, the discussion on educational programme in child care centres is in line with the principles of Islam which places high attention in child education. With increasing knowledge and awareness on the importance of Islamic values to be instilled from the early years of a child, more parents are now seeking for Islamic child care services. It appears that, in choosing private pre-schools, parents tend to choose pre-schools which are religion-based (Mohed et al., 2015).

Nowadays, some child care centres opt for an Islamic approach. Besides that, home schooling is also an alternative that is preferred by parents who see that it is hard to find child care centres which are Syariah compliance and at the same time to instil Islamic values in their children. It is heartening to see that some of the parents are able to train their children as early as three years old to memorise the Al-Quran. Therefore, a Syariah compliance child care centre may be an alternative in providing quality childhood education to the children. The curriculum used in pre-schools should inserted Islamic education as to expose the children to Islamic values and knowledge since early childhood (Mohed et al., 2015). 


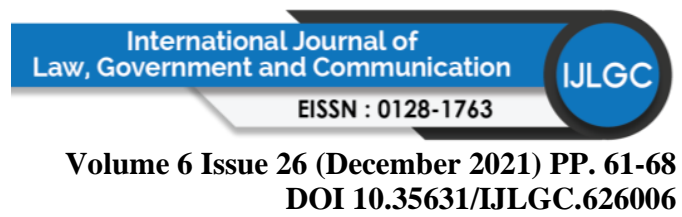

The early intervention programmes for the children, the play materials, equipment, and the environment should be Syariah compliance. Besides that, one of the important features is the value that is instilled in the child care providers. They are the ones who should first be motivated to foster the Syariah spirit in the centre. It is more than just portraying themselves in Islamic appearances. They need to be instilled with Islamic values in their words and actions.

\section{Conclusion}

Meanwhile, with regard to educational programme, in creating the curriculum, there is a need to take into account the values, cultures and traits of the country concerned. This is the consideration made by New Zealand and South Korea in promoting local values and cultures in the curriculum. Therefore, in adapting the curriculum from other countries, it cannot be simply transplanted without taking into account the local features. Lessons may be learned from other countries' experiences (Economist Intelligence Unit \& Lien Foundation, 2012). Besides that, in ensuring that this feature in the education programme is successfully regulated and implemented, other supplementary features such as ratio, group size, staffing issues including good continuous training for professional development need to be strengthened and well regulated.

Section 8 (e) of Malaysia CCCA 1984 may be revised and improved not just to touch on schedule of routine activities but also to include activities according to approved curriculum or framework. Furthermore, the elaboration on educational programme needs to be inserted and further clarified in Regulation 38 (1) (a) to specify the learning outcomes that are expected to be achieved by regulating the education programme in child care centres.

As practised by Australia, there is a need to have a clear law obligating the operators and child care providers to implement programmes that are based on approved learning frameworks. The law should highlight on what features should be focused on suitable to the culture and localities in the country. The importance for the implementation of educational programme for the children may be stressed by making it an offence for any failure to implement the educational programme in their centres. The regulations furthermore may specify the required outcomes and assessment system in assessing whether the outcomes are achieved or otherwise.

The documents of frameworks too must be easily understandable to the providers, for them not to feel burden in implementing the frameworks yet feel that they are assisted in planning activities for the children as there are systematic guidance available for them.

Thus, it is proposed that legislative effort in improving the quality of Malaysian child care centres need to touch on the legal requirements regarding physical environment, health and safety and adding a new feature of educational programme in Malaysian laws and regulations on child care centres.

\section{References}

Australian Children's Education and Care Quality Authority. (2017). Revised National Quality Standard and other Changes.

Bahagian Pendidikan Awal Kanak-Kanak PERMATA. (2013). Kurikulum Permata Negara (pp. 1-160).

Burchinal, M., Magnuson, K., Powell, D., \& Hong, S. S. (2015). Early Childcare and Education. Handbook of Child Psychology and Developmental Science, Vol. 4: 


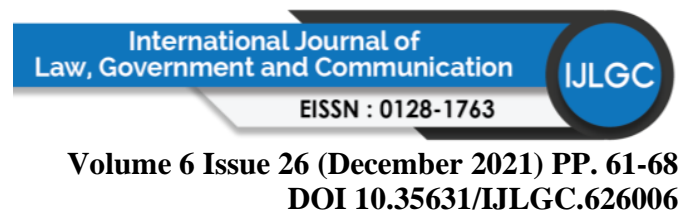

Ecological Settings and Processes (7th Ed.)., 223-267. http://ovidsp.ovid.com/ovidweb.cgi?T=JS\&PAGE=reference $\& D=p s y c 12 \& N E W S=N$ $\& \mathrm{AN}=2015-15587-006$

Debbie, C., \& McCormilla, L. (2012). Effective Curriculum Planning and Documentation Methods In Education and Care Services.

Economist Intelligence Unit, \& Lien Foundation. (2012). Starting Well. Benchmarking Early Education Across The World. A Report from the Economist Intelligence Unit.

Gallagher, J. J., Rooney, R., \& Campbell, S. (1999). Child Care Licensing Regulations and Child Care Quality in Four States. Early Childhood Research Quarterly, 1(3), 313-333.

Hanafi, Z. (2015). The Childcare Center: How to Ensure Quality Childcare Practices. Asian Social Science, 11(25). https://doi.org/10.5539/ass.v11n25p90

Mohed, M. M., Ismail, N. A., Utaberta, N., Yazid, M., \& Yunos, M. (2015). Understanding Islamic Education For Pre-School Children in Malaysia. Advances in Enviromental Biology, 9(24), 118-120.

Oberhuemer, P. (2005). International Perspectives on Early Childhood Curricula. International Journal of Early Childhood, 37(1), 27-37.

OECD. (2012). Starting Strong III: A Quality Toolbox for Early Childhood Education and Care. https://doi.org/http://dx.doi.org/10.1787/25216031

Rhee, O., \& Duksung, E. (2007). Childcare Policy in Korea : Current Status and Major Issues. International Journal of Child Care and Education Policy, 1(1), 59-72.

Slot, P. L., Leseman, P. P. M., Verhagen, J., \& Mulder, H. (2015). Associations Between Structural Quality Aspects and Process Quality in Dutch Early Childhood Education and Care Settings. Early Childhood Research Quarterly, 33, 64-76. https://doi.org/10.1016/j.ecresq.2015.06.001

Taguma, M., Litjens, I., \& Makowiecki, K. (2012). Quality Matters in Early Childhood Education and Care Portugal.

Taguma, M., Litjens, I., \& Makowiecki, K. (2013). Quality Matters in Early Childhood Education and Care Norway.

UNITAR International University. (2017). Laporan Akhir Kajian Perkhidmatan Taman Asuhan Kanak-Kanak (TASKA) di Malaysia.

United Kingdom Department for Education. (2017). Statutory Framework for the Early Years Foundation Stage: Setting the standards for Learning, Development and Care for Children from Birth to Five (Issue March). https://doi.org/00266-2008BKT-EN

United Kingdom Department of Education. (2013). International Evidence on Childcare Policies and Practices Research report (Issue July). https://www.gov.uk/government/uploads/system/uploads/attachment_data/file/212614 /DFE-RR285.pdf 